\title{
Open innovation for sustainability lessons from the greenxchange experience, an ictsd policy brief
}

\author{
Roya Ghafele*, Robert D. O'Brien \\ The University of Oxford; Oxford, UK \\ Email address: \\ roya.ghafele@sbs.ox.ac.uk (R. Ghafele)
}

To cite this article:

Roya Ghafele, Robert D. O'Brien. Open Innovation for Sustainability Lessons from the GreenXchange Experience, An ICTSD Policy Brief. International Journal of Economic Behavior and Organization. Vol. 1, No. 1, 2013, pp. 13-19. doi: 10.11648/j.ijebo.20130101.12

\begin{abstract}
The following policy brief discusses the natural experiment of 'GreenXchange' in the context of open innovation. Open innovation is a phrase popularized by Berkeley professor Henry Chesbrough who argues that firms should externalize R\&D and other innovative activity for the sake of technological advancement. And GreenXchange was a Web-based program allowing for firms to share their intellectual property for the sake of sustainable innovation under the open innovation paradigm. Our research indicates that the mild success of GreenXchange demonstrates a gap between academic ideas and their utilization in practice.
\end{abstract}

Keywords: Intellectual Property, Open Innovation, Sustainability

\section{Introduction}

Open innovation, a concept which was first created by Henry Chesbrough in 2003, has been the subject of increased interest in policy debates and academic studies. In recent years, it has been raised in a number of international fora. For example, the World Intellectual Property Organization's Development Agenda (WIPO DA), an initiative aimed at mainstreaming the development dimension in all of WIPO's activities, has sought to bring greater attention to the idea. Indeed, one of the 2007 WIPO DA recommendations calls for "exchanging experiences on open collaborative projects such as the Human Genome Project as well as on intellectual property models."1Open innovation has also been cited extensively, with a Google search of the term yielding nearly 600 million results. However, despite its rising popularity, open innovation has received relatively limited attention in the discussion of how to implement 'green' innovation, a fact which is of particular relevance within the context of the 20-22 June Rio+20 summit in Brazil.

The GreenXchange (GX), which was launched in 2010 by Nike along with nine other organizations, is an important

${ }^{1}$ http://www.wipo.int/ip-development/en/agenda/recommendations.html. In 2010, a project was adopted with the aim to "map/examine existing paradigmatic open collaborative initiatives and their relations with IP models through a taxonomy -analytical study." exception to this trend. The GX, a web-based marketplace for intellectual property (IP), was founded on the "belief that the best way to stimulate sustainable innovation is through open innovation" [1].

Two years after its launch, it appears timely to have a closer look at the GX. In effect, the GX appears not to have lived up entirely to the original expectations set out at its creation. Other than Nike, only one other company - Best Buy - has agreed to place its IP assets on the GX and the vast majority of the posted IP cannot be used in the creation of commercial products. These results prompt a number of questions:

In what ways does the GX exemplify both the usefulness and limitations of open innovation for sustainability? What lessons can be drawn from the GX experience in terms of the broader thinking on innovation, intellectual property and sustainability? And in what way can such initiatives be made to function better?

In order to answer these questions, a review of the existing literature on the GX was completed and stakeholders in the GX were interviewed. The findings are presented as follows: First, the mechanisms underwriting the GreenXchange will be introduced and examined. Second, the GX will be discussed within the broader context of 'green' open innovation. Third, the development of the exchange will be detailed and challenges to its success will be identified. Finally, recommendations will be offered on how to ensure the success of projects such as the GX moving forward.

Ultimately, though the GX has failed to catapult open 
innovation to a place of prominence in efforts to achieve greater sustainability, its development represents tentative first steps in the right direction. The story of its evolution is indicative of the fact that organizations, be they governments, non-profits, or private enterprises, can improve GX-like efforts to inspire a greener future using open innovation through: a) further education on the benefit of IP exchanges; b) an increase in resources dedicated to these exchanges; and c) a move away from focusing on simply the legal exchange of patents and toward collaboration between innovators.

\section{Using Sustainability to Open Up Intellectual Property: Can it work?}

In order to assess the development of the GX, it is first important to take note of its origins. The idea for the GX was first conceived in 2009, when some of the GX's founders realized that sustainability was becoming a more fundamental issue to businesses. Such a development was the result of, in some cases, new regulations requiring businesses to change their operations so as to be more environmentally friendly, and, in other cases, the advent of limitations on access to resources used in production. Motivated by this, the GX's founders discussed the best way to create an interactive platform that promoted the open exchange of best practices on issues related to sustainability. The fundamental idea that emerged was the creation of a system in which tested solutions - existing patents related to sustainability held by corporations and universities - could be shared using the open source community model for licensing pioneered by Creative Commons [2].

The GreenXchange, then, was born out of a motivation to solve larger problems related to sustainable business practices, with IP licensing in an online exchange chosen as the vehicle by which such problems could be addressed. It is within this broader context that its development should be assessed.

On January 27, 2010, Nike, along with nine other organizations - Yahoo!, Best Buy, Creative Commons, IDEO, Mountain Equipment Co-op, nGenera, Outdoor Industry Association, salesforce.com, and 2degrees - unveiled the GX at the annual World Economic Forum in Davos.

In the documents on the GX distributed at Davos, Nike stated that "[they] know it can work, because it already has." Here, Nike is referencing its archetypal case of successful IP licensing in the name of sustainability - the use of its "Environmentally Preferred Rubber" (EPR) in the production of bicycle tire inner- tubes manufactured by Mountain Equipment Co-op. The deal between the two companies is simple - Mountain Equipment Co-op pays Nike a licensing fee and, in return, receives the rights to use Nike's EPR, which contains 96 per cent fewer toxins than the company's original footwear rubber formulation [1]. Mountain Equipment Co-op then uses the EPR in manufacturing bicycle tire inner-tubes. The result is a win-win situation, with
Nike earning money off its patent and Mountain Co-op reducing its carbon emissions, improving factory conditions, and delivering a greener product to its customers [3].

With this experience under its belt, Nike and its partners promoted the GX as a mechanism for promoting sustainability-related innovation through IP licensing. In order to kick-start the platform's development, Nike President and CEO Mark Porter pledged to place more than 400 of the company's patents on GX [1].

\section{The Greenxchange: "Our Model is Open Innovation, Our Methods are Those of the Digital Commons"}

In announcing the creation of the GX, Creative Commons stated that "our model is open innovation, our methods are those of the digital commons." Dan Tapscott, who helped in the formulation of GX, later noted that "the exchange is a web- based marketplace where companies can collaborate and share intellectual property which can lead to new sustainability business models and innovation" [1]. But how exactly does the GX work?

In short, the exchange combines technology and the Creative Commons licensing structure to provide a platform for companies to both issue licenses to use their patents and acquire the rights to use the patents of others [4]. The mechanism devised for this sharing of intellectual property is known as the "GX semi-structured public license." Formulated using the Creative Commons philosophy of "some rights reserved," it allows the owners of the IP to control what aspects of their patents are accessed while offering those who are interested in the patent the opportunity to acquire the rights to use it in their own research. The founders of the exchange state that it will "anticipate common transactions and lower the transaction costs for those rights that a patent owner may want to put into play, while reserving others" [3].

Those wishing to post IP on the GX can choose to classify it under three different licensing structures: a standard option, a standard PLUS option, and a research nonexempt option.

The standard option offers GX users the chance to obtain a royalty-free license under which they can commercially use the patented technology. In other words, the owner of the IP is willing to give it away and the users can utilize it however they wish. The standard PLUS option, the most complicated of the three structures, gives GX users the opportunity to acquire a license that requires a payment and/or features restrictions. Under this option, the patent holder posting the license to the exchange can require a payment for its use or place specific restrictions on its use [5]. For example, the University of California at Berkeley posted a patent related to healthcare on GX using the standard PLUS option, indicating that it could only be used in creating a marketable product by persons from developing countries [2]. The research non-exempt option provides nonprofits the 
opportunity to conduct research on the posted patented technology, improve and adapt it, and then patent these improvements and adaptations for noncommercial use. This option allows companies to post assets without fear of them being used later in products produced by competitors. At the same time, it provides non-profit institutions such as universities the opportunity to access existing patents, improve them, and then patent these improvements [5].

In creating this licensing protocol, GX developers hoped to mitigate the concerns of IP holders regarding patent protection while simultaneously encouraging them to license it out. It was their hope that the protocol would make possible the type of web-based platform that stimulates innovation in the realm of sustainability. By using Creative Commons to develop the protocol, GX's founders established the licensing structure as a public good that is available for use by anyone regardless of whether they work with the GX or not [2].

\section{Open and 'Green' Innovation, In- tellectual Property, and the Green- xchange $^{2}$}

There are different views on what constitutes open innovation, For some, it means the absence of IPRs, For others, it means pro-actively leveraging IP through a more open approach towards knowledge management [6], [7]. This is the original meaning used by Chesbrough when he coined the term 'open innovation.' From this perspective, intellectual property is not limited to internal development, but can also be sold, licensed, or even given away for free [8], [9].

Firms also have the opportunity to nurture their own innovation by acquiring IP from others. Licensing IP is an important means to open up the innovation process itself and support technology transfer. Under an open innovation paradigm, companies should license in technology that supplements their business model and license out IP that they do not deem necessary for corporate performance. An open innovation approach towards IP stands thus in contrast to a 'Cold War' IP paradigm, where patents are essentially held as a 'weapon of mass destruction' and as a means to attack, counter attack and defend the company from third party aggression. An open innovation approach towards IP proposes a more 'peaceful' leverage of IP; one that is rooted in the logic of profit, growth rates and market share, rather than in an unfortunate imitation of a 'nuclear arms race.'

An open innovation approach of IP stands in contrast to the established view that sees IP as a defensive right that serves to keep competitors at bay through litigation or the threat of litigation. There is however a new school of

\footnotetext{
2 This chapter draws upon: Roya Ghafele, James Malackowski \& Benjamin Gibert. Emerging IP Monetization Techniques. The Institutionalization of an Intellectual Property Exchange. Accepted by International Journal of Intellectual Property Management. 15. 5.2011.
}

thought emerging where the value proposition of IP is modeled through an 'intangible assets' lens. and patents are seen as a key variable to increase the efficacy of technology utilization and a vital enabler for the flourishing of secondary markets for technology [6].

A different understanding of the value proposition of IP gives way to different institutions, such as Nike's GreenXchange. While bilateral licensing negotiation has been the traditional mechanism for the transfer of patent rights in the past [10], [11], [12], new intermediaries are emerging that facilitate the transfer of technology. US Internal Revenue Service data shows that technology licensing payments increased from $\$ 33$ billion to $\$ 157$ billion between 1994 and 2007 [13]. While this growth in licensing revenue can be seen as an indicator of enhanced efficiency of technology utilization, the traditional bilateral licensing model may lack the necessary ubiquity and standardization to promote transparent, active and liquid markets for IP. It requires enormous amounts of often redundant due diligence, is time consuming and can be highly skewed according to the bargaining power of participants. Usually operating in a private and sequential bargaining context, it offers significant flexibility for both parties but the transaction costs of transferring technology between organizations can occasionally be so high as to mitigate the value generated [14]. All deals are the result of 'one-off' negotiations, essentially forcing parties to repeatedly go into enormous detail over every facet of the bargain in every licensing transaction. Traditional channels for licensing are simply not sufficient to sustain the influx and transparency needed of a working market for intangible asset rights trading [15]. There are no standards for licensing and bilateral negotiations effectively constitute a private market for IP valuation. This is partly because parties do not want increased transparency; lack of transparency in the IPR market may drive prices higher than if there is full disclosure. But at what cost? Says O'Brien: 'The value of intangible assets is becoming too large to trade in a clandestine market' [16]. Against this background the question arises how markets can be better organized and what can be done to move from a clandestine bilateral licensing model to one where IP is traded in a transparent manner. An electronic platform that allows for the trading of IP by multiple partners in a transparent manner seems thus a way to overcome this dilemma.

It enables the monetization of non- or under- utilized patents via mechanisms other than bilateral licensing or litigation and simultaneously encourages investment in the development of patentable inventions. An IPRs exchange may be compared to a marketplace that aggregates buyers and sellers where the commodity in question goes to the highest bidder who is able to draw on knowledge of the historical pricing of similar commodities It could thus be a route to overcome many of the shortcomings associated with the traditional bilateral licensing model, foster transparency and promote the transfer of technology. It may however also trigger litigation. Yet, in spite of such challenges, it should reduce volatility and costs of capital for innovative firms. The GreenXchange can thus be read as an effort to not to 
promote IP under an open innovation paradigm.

\section{The development of the GreenX- change: challenges and adjustments}

When it was launched in 2010, the GX was presented as an innovative new approach to knowledge sharing aimed at promoting more sustainable business practices .Two years after its creation, the GX is home to just 463 patents: 444 of those were posted by Nike soon after it launched the exchange, 15 were subsequently posted by Best Buy, and four were posted by the University of California at Berkeley [5].These numbers make clear the fact that since its unveiling, the GX's founders have encountered several challenges to realizing their initial objectives. These challenges have led Nike to reconceptualise its short-term goals for the GX, though the company remains committed to its long-term objective of serving as a widely-used web-based marketplace for IP transactions that promote sustainability.

Three challenges in particular stand out in efforts to develop the GX:

the strength of the prevailing paradigm on IP protection and management;

the realization that patents in and of themselves are not necessarily the most integral part of open innovation-inspired attempts to promote sustainability business models; and

limited resources given the scope and scale of the project.

The first such challenge was a general lack of consensus amongst patent holders regarding the safety and utility of IP licensing and exchanges [17]. This is not a problem unique to the GX. Efforts to establish a secondary market for IP have been made before and exchanges such as Yet2com have failed to achieve success. 3 As one individual intimately familiar with the development of the GX noted, the idea behind the exchange, and indeed all such IP transaction platforms, runs completely contrary to the conception of IP held by most patent owners, including businesses and universities. They look at patents as a means to assure 'freedom to operate', allowing them to block competitors in a given market segment, as well as mitigate risk.

One of the ways that the founders of the GX attempted to address this challenge was by targeting universities as potential contributors to and beneficiaries of the exchange [2], [17]. Universities hold large numbers of patents, but, unlike larger corporations, they often lack the resources to create economic value out of their patent holdings. The GX, then, would seem to be the perfect platform by which they could find a means to turn their dormant and underutilized patents

\footnotetext{
${ }^{3}$ Another newly established platform for trading IP, IPXI, has recently received 10 Million USD from Philips, the Chicago based options exchange and third investor who prefers to remain anonymous. It will remain to be seen to what extent IPXI will break the spell over IP exchanges.
}

into the seeds of successful inventions. Through the GX, they could both license existing IP that would allow them to further enhance their own innovative projects and license out stocks of their own unused or underused IP. The GX would also offer them the opportunity to identify potential partners in research and development, whether they were other universities or large corporations, such as Nike, with the revenue flow to finance further R\&D efforts.

To encourage universities to make use of the exchange, the GX's developers reached out to number of major institutions of higher learning, including UC-Berkeley, the University of Washington, the University of Arizona, and the University of Oregon. They found some success in their dealings with Berkeley, who committed four patents to the GX. In general, however, interactions with these universities led GX employees to realize that in order for the exchange to be of true value to such major research institutions, it would need to maintain a very large number of patents. Universities are typically looking for very particular patents to access and not just acquiring and offloading IP of potential interest. Thus, an exchange with only a small number of patents is not likely to be particularly useful to them [2]. The GX, then, faced a classic dilemma - it needed a large number of patents to interest universities and it needed universities to contribute IP to realize a high volume of patents. A solution to this problem has yet to be discovered.

The second challenge encountered by the developers of the GX was the realization that their initial focus on the tangible exchange of patents may have been misplaced. Through their interactions with both businesses and universities, the founders of the GX discovered that there was more interest in gaining access to the knowledge behind the creation of the patents than there was in simply obtaining the patents themselves. Businesses and universities, it seemed, viewed the patent more as a gateway to the inventor(s) than as an asset with its own inherent value. This realization led to a radical reconceptualization of the trajectory of the GX, away from a focus on accruing assets on a web-based platform and toward an emphasis on building relationships between parties with mutual interests and mutually beneficial knowledge regarding sustainability [2], [17].

The fact that the original conception of the GX might not facilitate the attainment of the goals set out by Nike and the GX's founders was made most clear through Nike's efforts to license out the use of its EPR. The company had already been successful once in this enterprise, providing the patent to Mountain Co-op for use in the production of bicycle tire inner-tubes. GX employees attempted to leverage this success by offering Nike's EPR to a number of companies, including competitors in the footwear industry. Nike structured the license for its EPR as a "standard-plus," requiring those who wished to use its product to register how they used it. Nike also required access to any improvements made on the EPR by other organizations [2].

During the process of offering Nike's EPR for license, GX developers quickly discovered that the other footwear companies were more interested in access to the people 
behind the patent than they were in the patent itself. The patent still served a purpose - it regulated the relationship between Nike innovation specialists and those in other footwear companies in order to make interaction and collaboration safe - but it was not the focus of the exchange. This new dimension of the GX also seemed to yield additional benefits. Once the two sides were talking, relationships were built and conversations naturally and organically broadened to include potential new areas of collaboration [2]. On January 11, 2011, the GX held an in-person collaborator with representatives of various athletic footwear companies, non-profits, universities, and government agencies. The focus of the session was on technical assistance for companies licensing Nike's EPR through the GX, but the conversation later broadened to include discussion of collective action designed to solve sustainability challenges related to packaging, product recycling, water-based adhesives, "green leather," and manufacturing facility energy efficiency [18].

This general desire among businesses for access not simply to patents, but also to the people behind the patents, was also demonstrated by university researchers. The result was a radical reconceptualization of the GX which included several changes to its extant model. First, the short-term focus of the GX's developers was changed from emphasizing asset accrual to an effort to build relationships around the assets already posted to the Exchange. Second, the entire project, already heavily attached to Nike, became even more Nike-centric, with the company taking the stance that if it could figure out how exactly the GX should be used it could later serve as a model for the adoption of the GX by other companies. In short, while the long-term vision for the GX as a web-based platform for IP exchanges and, more generally, the importance of IP licensing in promoting sustainability in business practices, has not been modified, the path to achieving such a goal has been shifted [17], [2].

Throughout the development of the GX, it has faced a third challenge - general resource limitations. The GX set out to challenge a dominant paradigm in conceptualizing IP, hoping to leverage the combination of open innovation and the Creative Commons licensing structure to promote patent exchanges aimed at achieving more sustainable business practices. Needless to say, such ideals require significant resources to achieve. Yet, combining the percentage of work dedicated to the exchange by different employees at the different founders, roughly a total of two people were committed to the development of the GX full-time [2]. Such a fact seems to have posed problems both before and after the reconceptualization of the GX.

Initially, when the GX was focused on developing a web-platform and accruing assets, this led to an extremely slow pace of website development. The exchange has already been housed on two different web platforms and, as of 20 May 2012, the latest iteration offers only limited information on the assets. While users can see how many assets are on the GX, the distribution of license structures, who contributed the assets, and what general category they fall under, they cannot access any information providing an overview of the content of the assets. Users also cannot acquire assets or post assets without going through an exchange employee [5].

Since the developers of the GX realized that it should be more focused on relationship- building around assets, the venture has become arguably even more work-intensive. After all, it requires more effort to nurture and regulate relationships between two or more parties than it does to moderate a website.

Those intimately acquainted with the GX's founders and operations praise the commitments made by these companies to its success and development [2]. That being said, given the ambitious mission set out by the consortium and the slow pace at which the exchange has developed, it is evident that the amount of resources dedicated to the GX has been insufficient.

The GreenXchange represents a novel attempt to solve pressing issues related to sustainability in business practices. Based on the way it was presented to the world in January 2010, the GX has been to a certain extent unsuccessful. However, the avant- garde nature of its work and the story of its development offer valuable insights to those looking to utilize open innovation in promoting sustainability business models.

\section{Conclusion: Using Open Innovation to Achieve Sustainability}

The GreenXchange was introduced at a time when a consensus amongst academics and innovation experts was beginning to form around the idea that by reducing privileged access to technology and the need for complementary assets, a liquid marketplace for patents should engender a more productive division of labor that both results in a more efficient commercialization of new technologies and promotes sustainability. Yet, the GX's development story is indicative of a reality in which there remains a chasm between scientific thought and real-world practice when it comes to intellectual property management. This prompts the question of what can be done to close that gap. Here, the challenges faced by both the GX and other intellectual property exchanges are instructive, suggesting three clear paths forward:

\subsection{Increasing Education on the Benefits of Open In- novation-Inspired IP Exchanges}

The developers of the GX encountered a familiar problem - a century old paradigm which holds that IP is not a readily tradable asset class. At the center of this paradigm stands the conservative, legal perspective on the utility of intellectual property. It will take time to change these established patterns of thought, but efforts to educate the business world as to the benefits of IP exchanges such as the GX will yield results. Since many of the innovative thinking in this realm emanates from academics, they will likely lead the way in shaping the views of tomorrow's business leaders on intel- 
lectual property. Ultimately, though, the exchanges themselves will be charged with educating potential users on the benefits of the platform they created. This reality leads to this paper's second major finding.

\subsection{Significant Resources Will Be Needed to Change the Dominant IP Paradigm}

Such a realization has major implications for structuring projects such as the GX in the future. In order to replace the existing view of IP with one that is more in line with the open innovation-inspired model advanced by the GX, significant resources will be required in terms of both manpower and financial assets. Herein governments may play a role. Those governments wishing to support efforts to promote innovation via IP licensing, particularly when it is aimed at achieving greater sustainability in business practices, can do so in several ways. First, they can devise a tax credit for businesses who place their IP on exchanges like the GX. This would provide an extra incentive for these businesses to both manage their IP in a more efficient manner and open up access to patents they hold which are not integral to their business model, but that may be helpful at promoting innovation elsewhere. Governments could also play a role in a public-private-partnership (PPP), whereby they provide resources, in the form of funding or manpower, and private enterprises such as Nike provide expertise in their field, their connections, and the business perspective on why IP licensing stands to benefit the corporate world. Such a PPP could manifest as an IP exchange, like the GX, that is established as a foundation with both government and private-sector support.

\subsection{Connecting People is Just as Important, if Not More Important, Than Exchanging Patents}

Perhaps the most important take away from the GX's development is the fact that connecting the innovators behind patents is viewed by many enterprises as of greater importance than simply acquiring the legal rights to use a patent. With this in mind, IP exchanges need to place more emphasis on relationship building aimed at collaboration between companies. Nike's efforts to accomplish this task using its own store of patents is notable and seems to be yielding results, even if they have been only modest thus far. Building on Nike's findings, IP exchanges need to broaden their focus to include convening conferences, setting up seminars, and sponsoring other forms of physical interaction. While web-based platforms are one important aspect of these exchanges, they do not appear to be a panacea to the problems that exchanges such as the GX have faced. Here, again, resources are key and a PPP would serve these efforts well.

When interviewed by The Financial Times in late 2010, 11 months after the launch of the GX, Hannah Jones, vice president of sustainable innovation at Nike, noted that "all of this is nascent," going on to promise that "we shall embrace the failures and experiment wholeheartedly" [19]. By all accounts, Nike and its partners have backed up Jones' comments with action. In the process, the GX's developers have encountered challenges that provide insight into how IP exchanges, particularly those focused on promoting green innovation, should be structured moving forward. Though the GX has not lived up to its billing, it provides a strong foundation from which the effort to change the dominant intellectual property paradigm in order to inspire innovation can be pursued. The story of its development and the lessons it yields are particularly relevant within the context of the Rio+20 summit, which seeks to discover how to best leverage innovation for sustainability.

There is no proverbial silver bullet that will turn past IP exchanges' failures into future successes overnight. Yet, by focusing on increased education as to the benefits of IP licensing and exchanges for innovation, forming partnerships so as to accumulate more resources for these exchanges, and broadening the emphasis of their development to include efforts to connect the innovative people behind the patents, projects such as the GX can pave the way to a brighter, greener, and more innovative future.

\section{References}

[1] Tapscott, Dan (2010) Bloomberg Businessweek January 27. Availablefrom:

$<$ http://www.businessweek.com/the_thread/techbeat/archi ves/2010/01/davos ni ke an d.html $>$ (accessed 21 May 2012).

[2] GX consultant (2012). Interview conducted on 17 May 2012.

[3] 'The GreenXchange' (2010) Davos hand-out produced by Nike and Creative Commons. Available from: <http://sci encecommons.org/wp-content/upl oads/GX - Davos-Booklet.pdf> (accessed 19 May 2012).

[4] Mazur, Agnes (2009) 'Green Exchange: Creating a Meta-Map of Sustai nability', WorldChanging May 5. Available from: <http://www.worldchanging.com/archives/009822. $\mathrm{html}>$ (accessed 22 May 2012).

[5] Greenxchange.cc (2012) 'The GreenXchange: Accelerating sustainable innovation through IP sharing' (official website of the GreenXchange). Available from: $<$ http://greenxchange.cc/> (accessed 23 May 2012).

[6] Chesbrough, H. 2006. Emerging secondary markets for Intellectual Property. Research Report to National Center for Industrial Property Information and Traning (NCIPI).

[7] Lord, M.D., Mandel, S.W., and Wager, J.D. 2002. 'Spinning out a Star', Harvard Business Review. June 2002.

[8] Christensen, J.F., Olesen, M.H. and Kjær, J.S. 2005. "The Industrial Dynamics of Open Innovation - Evidence from the transformation of consumer electronics." Research Policy, 34, 10 (December): 1533-1549.

[9] De Jong, Jeroen P. J., Kalvet, Tarmo, and Vanhaverbeke, Wim. "Exploring a theoretical framework to structure policy implications of OI." Technology Analysis \& Strategic Management 22 (8): p. $877-896$. 
[10] Caves, R. E, H. Crookell, and J. P Killing. 1983.The Imperfect Market for Technology Licenses. Oxford Bulletin of Economics and statistics 45, no. 3: 249-267.

[11] Teece, David J. 1986. Profiting from technological innovation: Implications for integration, collaboration, licensing and public policy. Research Policy 15, no. 6 (December): 285-305. doi :10.1016/0048-7333(86)90027-2.

[12] Arora, A. 1995. Licensing tacit knowledge: intellectual property rights and the market for know-how. Economics of innovation and new technology 4, no. 1: 41-60.

[13] Parr, R. 2007. Royalty Rates for Licensing Intellectual Property, at pg. 18-19, John Wiley \& Sons, New York.

[14] Teece, D. J. 1988. Technological change and the nature of the firm. Technical change and economic theory: 256.
[15] McClure, I. D. 2008. Commoditizing Intellectual Property Rights: The Practicability of a Commercialized and Transparent International IPR Market and the Need for International Standards. Buffalo Intellectual Property Law Journal 6: 1.

[16] O'Brien, K. 2007. The first intellectual property rights auction in Europe will be held in Munich. New York Times.

[17] Nike employee (2012). Interview conducted on 11 May

[18] 'GreenXchange: Partners Collaboratory' (2011). Greenxchange.cc January 23. Available from: $<$ http://greenxchange.cc/i nfo/rel ease/1-23-2011> (accessed 23 May 2012).

[19] Broughton, P.D. 2010. "Another form of creative thinking" The Financial Times, November 17, 2010. 